\title{
Artigo
}

\section{O Brasil na iniciativa BRIC: soft balancing numa ordem global em mudança?}

Brazil in the BRIC initiative: soft balancing in the shifting world order?

DANIEL FLEMES*

Rev. Bras. Polít. Int. 53 (1): 141-156 [2010]

\section{Ponto de partida: uma ordem global em mudança}

Estados que atuam como líderes internacionais no que diz respeito à normatização de regras têm especial importância quando são necessárias medidas para enfrentar problemas transnacionais. Isto implica tanto questôes relacionadas ao comércio mundial como também aos riscos de segurança internacional. As tentativas destas políticas para resolver os problemas podem ser organizadas a nível regional e global. Em ambos os casos, alguns atores estatais desempenham um papel mais importante do que outros no âmbito da cooperação e dos processos de negociação e, portanto, têm maior influência sobre os resultados. A razão pode ser o maior potencial militar ou econômico destes atores. Da mesma forma a sua legitimidade, eficácia diplomática, autoridade moral, bem como sua função representativa em uma região ou grupo de Estados podem gerar vantagens nas negociações internacionais.

Recentemente, muitos estudos têm apontado mudanças de poder mundial em favor dos BRICs e outras potências emergentes (Goldman Sachs: 2007; Cooper e Antkeiwicz: 2008; Mahbubani: 2008). Os atuais pólos de poder existentes na Europa e na América do Norte estão sujeitos a sofrer uma perda relativa de seus poderes militares e econômicos, inclusive a dominação da cultura ocidental e seus valores é contestada (Cox: 2007; Ikenberry: 2008; Zakaria: 2008). O crescente protagonismo das potências emergentes na economia mundial e na governança global após a bipolarização tem sido discutido sob os rótulos de potências emergentes, grandes potências, potências médias e Estados centrais (Chase, Hill e Kennedy: 1996; Schoeman: 2003; Hakim: 2004; Soares de Lima e Hirst: 2006; Hurrell: 2006; Flemes: 2008).

\footnotetext{
* Pesquisador do GIGA - German Institute of Global and Area Studies, Alemanha (flemes@giga-hamburg.de).
} 
Debates relacionados acentuam a ascensão e queda dos hyperpowers (César: 2008) e a teoria da transição de poder, que são focados em formas específicas de conflito que foram geradas entre Estados em ascensão e potências estabelecidas (Organski e Kugler: 1980; Gilpin: 1981; Tammen et al.: 2000). A mesma questão foi abordada na perspectiva da geopolítica (Overholt: 2008) e das hierarquias de poder internacional (Lake: 2007). O recente debate sobre unipolaridade (Ikenberry, Mastanduno e Wohlforth: 2009) centra-se no argumento neo-realista, no qual ambos os poderes, estabelecidos e emergentes, buscam a dominação hegemônica na sua própria região e o enfraquecimento da posição dos outros poderes dentro de suas regiōes (Wohlforth: 1999; Huntington: 1999; Mearsheimer: 2001). A teoria do balanço de poder prediz que os Estados irão responder ao poder concentrado por vários tipos de power balancing (Waltz: 2000; Levy: 2003; Pape: 2005; Lieber e Alexander: 2005). Outros artigos questionam se a transformação sistêmica irá conduzir a um "cartel de potências" (Kagan: 2008), a um "mundo não-polar" (Haas: 2008), à "multipolaridade instável" (Humphrey/Messner: 2006) ou à "multi-multipolaridade" (Friedberg: 1994; Nolte: 2008) ou a uma "ordem mundial multi-regional" (Hurrell: 2007; Flemes: 2008).

No entanto, o ponto de partida é a atual ordem global, que reflete uma mistura de concerto de grandes potências e estruturas multi-regionais. A atual ordem global é constituída, de um lado, pela União Europeia (UE) como uma região relativamente funcional e, por outro lado, de muitas grandes potências sem regiōes funcionais, como são os Estado Unidos, a China, a Rússia e a Índia. Em comparação, o Brasil é econômica, politica e culturalmente muito mais interligado à sua região. $\mathrm{O}$ país também fornece bens coletivos de relativa estabilidade e segurança, bem como infra-estrutura regional, considerando que a China, Rússia e Índia são vistos como potenciais ameaças por parte de alguns dos seus vizinhos regionais. Por outro lado, o Brasil não está disposto, ao contrário das potências europeias, a construir instituiçōes regionais democráticas e representativas, incluindo processos participativos de tomada de decisão. Pode-se dizer, então, que o Brasil está numa encruzilhada e pode prosseguir ativamente suas estratégias globais com ou sem a sua região.

As escolhas e as estratégias dos tomadores de decisão quanto a política exterior brasileira afetarão o balanço entre os conceitos de ordem global anteriormente mencionados (Cervo: 2006). A posição das potências do Sul, como o Brasil, que está, por um lado, entre o centro e a periferia da atual ordem mundial e, por outro lado, na interface da política internacional com a regional, demanda estratégias de política externa particularmente complexas. Abordagens estratégicas deveriam considerar, pelo menos, três fatores contextuais: primeiro, a superioridade continuada dos atores globais estabelecidos (Estados Unidos) e emergentes (China) em termos de poder material; em segundo lugar, o fato de assuntos regionais e globais estarem cada vez mais inter-relacionados; por último, o fato de que as estratégias de política externa serem mapeadas contra o cenário de um sistema internacional que se desloca de uma ordem unipolar a uma ordem multipolar. 
O Brasil, ao contrário dos Estados Unidos, UE ou China, não pode esperar tornar-se uma potência dominante em qualquer futura ordem global, devido à sua escassez de recursos materiais. O país não é uma grande potência. Grandes potências são os países que, por meio de sua grande força econômica, política e militar, são capazes de exercer poder em âmbito global. Os seus pareceres devem ser considerados por outras naçôes antes que estas atuem diplomática e militarmente. Em contraste com as suas relaçóes com meras potências regionais, os demais Estados respondem às grandes potências com base em cálculos sobre a distribuição do poder no sistema internacional no presente e no futuro próximo (Buzan e Waever: 2003, 35). Hurrell (2006) menciona quatro critérios que caracterizam uma grande potência: 1) a capacidade de contribuir para a ordem internacional; 2) coesão interna que permite a ação do Estado eficaz; 3) poder econômico, tais como níveis elevados de crescimento econômico ou um grande mercado; 4) poder militar, com a capacidade de competir com outras potências dominantes em uma guerra convencional. E o Brasil, definitivamente, não atende a este último critério.

Portanto, não parece provável que, à primeira vista, a concepção brasileira da futura ordem mundial se caracterize por "anarquia e luta pelo poder" (Mearsheimer, 2001). Pelo contrário, as expectativas do Brasil quanto ao status de grande potência a médio prazo são alimentadas pelas previsões de crescimento econômico progressivas (Goldman Sachs, 2007). O Brasil ainda não está qualificado para entrar no clube das grandes potências, mas o seu governo não concorda em ser classificado junto com o "resto medíocre" e pretende reforçar a sua influência e prestígio para se tornar uma grande potência na futura ordem global. Se estes pressupostos são adequados, seria racional que Brasília pretendesse uma ordem global marcada pelo concerto das grandes potências. Nesse último caso, o objetivo primordial consistiria na ascensão do Brasil na hierarquia internacional de Estados relativamente independentes das práticas políticas aplicadas e do grau de institucionalição da ordem global. Nesse contexto, cada grande potência iria tentar maximizar a sua quota de poder, o que significa ganhar poder em detrimento dos outros Estados.

A fim de avaliar os possíveis cenários alternativos à ordem global, cálculos sistêmicos também devem ser levados em consideração. Neste sentido, o comportamento dos Estados Unidos e o seu posicionamento potencial na futura ordem global são de grande relevância. Não se pode esperar o declínio completo da superpotência a qualquer momento do futuro próximo. Pelo contrário, a distribuição global das capacidades militares, econômicas, de investigação e de desenvolvimento indica uma unipolaridade sistêmica que pode durar por muitas décadas (Ikenberry, Mastanduno e Wohlforth: 2009). Em particular, a superioridade militar dos Estados Unidos é muito acentuada e sua indústria bélica está beneficiando-se dos crescentes retornos de escala (Caverley: 2007). Adicionalmente, a mudança de governo dos Estados Unidos poderia dar a legitimidade internacional que acabou por desaparecer durante a administração 
de George W. Bush. Barack Obama pretenderá restaurar a autoridade moral dos Estados Unidos (Slaughter: 2009). O problema é que as potências emergentes como o Brasil não são confrontadas com apenas uma potência do status quo. Muitas grandes potências estabelecidas estão lutando para defender suas prerrogativas, protegidas por um denso sistema de relações econômicas, políticas e de segurança, incluindo uma comunidade de segurança entre algumas das principais potências (Ikenberry e Wright: 2008).

Estas observaçóes reforçam a perspectiva de um rearranjo das grandes potências, pelo qual se espera uma tendência conflitiva (Mearsheimer, 2001; Kagan, 2007). Três fatos sugerem a menor probabilidade de conflitos violentos entre as grandes potências do mundo. Primeiro, guerras de grandes potências como veículos de transição de poder não são prováveis, devido à posse e potencial de uso de armas nucleares. Sendo assim, a redistribuição violenta do poder seria um jogo de resultado nulo. Em segundo lugar, a ordem internacional existente é mais aberta, mais institucionalizada, consensual e mais fundamentada em regras do que o foram as antigas ordens internacionais. Assim, a partir da perspectiva das potências emergentes, é mais fácil entrar que derrubar a existente ordem, pois algumas medidas protetoras lhes são oferecidas (por exemplo, as normas anti-discriminatórias da Organização Mundial do Comércio - OMC), além da possibilidade de ascensão hierárquica nas instituições internacionais (Ikenberry e Wright: 2008). E em terceiro, a partir da perspectiva dos Estados Unidos, seria conveniente para o país fomentar instituiçóes globais, considerando que o seu papel hegemônico declinará nos próximos anos. O valor das regras e das instituições pode aumentar na medida em que essas regras podem ajudar a ancorá-los na ordem internacional preferida (Ikenberry: 2008). Pode-se esperar que os Estados Unidos reformem e consolidem instituições internacionais, permitindo-lhes persistir no período pós-hegemônico ao mesmo tempo refletindo seus próprios interesses e valores (Keohane: 1984; Ikenberry: 2001). Cálculos do nível sistêmico sugerem uma futura ordem global moldada por grandes potências, por meio de instituições internacionais.

\section{Soft balancing: formação de alianças flexíveis nas instituições globais}

Historicamente, a política externa brasileira pode ser dividida em duas tradiçōes. A primeira enfatiza as relaçōes com os Estados Unidos (Hirst: 2006) e a Europa (Rezende Martins e Gomes Saraiva: 2009), com o intuito de promover o comércio bilateral e receber reconhecimento internacional. A segunda baseia-se na identidade brasileira de país em desenvolvimento, e pretende construir uma rede de 'terceiro-mundismo' (Jaguaribe: 2005). A partir desta perspectiva, a prioridade do desenvolvimento e do multilateralismo é um legado que condiciona a política externa brasileira até hoje (Soares de Lima e Hirst: 2006). Os governos do presidente Lula da Silva têm sido bem-sucedidos em conectar essas duas tradições 
distintas, dando ênfase a uma 'política externa autônoma' (Soares de Lima: 2008, 64). A busca da autonomia 'deve levar à participação ativa do Brasil na criação e na aplicação de normas internacionais que são mais ligadas aos interesses e aos valores brasileiros' (Pinheiro Guimarães, 2006).

No entanto, as opções de política externa do Brasil são limitadas, tendo em conta a superioridade do atual poder hegemônico. Embora o Brasil goze de influência crescente, ainda é situado na periferia do sistema mundial atual e domina recursos materiais relativamente modestos. Uma razão crucial para a hegemonia dos Estados Unidos nas relações internacionais é a supremacia militar do País. Washington contribui com mais da metade dos gastos globais de defesa (SIPRI: 2008) e 60\% dos investimentos em investigação e de desenvolvimento mundiais (BICC: 2008). Em termos militares, os Estados Unidos continuarão a ser a potência global dominante por um longo tempo. Portanto, este não é o momento para hard balancing baseado em alianças militares (external balancing) e armamento (internal balancing).

Como argumenta Nye (2004), uma unipolaridade global real exige o domínio do poder hegemônico em dois campos de ação adicionais: na economia global e noutras questôes transnacionais como o terrorismo, a criminalidade, o aquecimento global, e as epidemias. Como a cúpula do G20 em Pittsburgh - um esforço central para combater a atual crise econômica - demonstrou, problemas transnacionais só podem ser resolvidos por meio da cooperação de muitos atores. Ignorar as economias emergentes, como muito foi feito no passado, já não é possível. Sem sua cooperação, esses problemas globais tendem a aumentar os impactos em todos os Estados, incluindo os Estados Unidos e outras nações ocidentais. Consequentemente, esses são os campos em que potências emergentes podem ganhar influência global, e cujo sucesso dependerá em grande parte da solidez com que a equipe trabalha. O Brasil e os outros países do BRIC já demonstraram capacidade para alcançar os seus objetivos, e, particularmente, os objetivos econômicos dentro da ordem existente. Em comparação, os ganhos que podem ser esperados a partir de um colapso violento da atual ordem internacional são muito limitados. Portanto, as estratégias institucionais parecem ser as mais promissoras para impactar a hierarquia internacional dos Estados.

Soft balancing não desafia diretamente a preponderância militar dos Estados Unidos, mas sim utiliza instrumentos não militares para retardar, frustrar e prejudicar as políticas unilaterais da superpotência (Pape: 2005, 10). Soft balancing envolve estratégias institucionais, tais como a formação de coalizões ou ententes diplomáticas limitadas, como BRIC, IBAS, G3 e G21, para restringir o poder das grandes potências estabelecidas. Esta estratégia institucional é também referida como buffering e tem como objetivo alargar o espaço de manobra dos Estados mais fracos frente aos Estados mais fortes (Greenfield Partem: 1983; Gries: 2005). Envolve também o reforço dos laços econômicos entre as potências emergentes, por meio da colaboração em diferentes setores. Isso poderia mudar o equilíbrio 
do poder econômico em médio prazo. Paul $(2005,59)$ define três pré-condições para o comportamento soft balancing: 1) A posição da potência hegemônica e o comportamento militar são de crescente preocupação, mas ainda não representam uma séria ameaça à soberania dos poderes secundários; 2) o Estado dominante é uma importante fonte de bens públicos nas áreas de economia e segurança, as quais não podem ser simplesmente substituídas; e 3) o Estado dominante não pode simplesmente retaliar, porque os esforços de equilíbrio dos outros não são evidentes ou porque não desafiam diretamente a sua posição de poder por meios militares. Ao perseguir soft balancing, Estados secundários poderiam engajar o poder hegemônico e desenvolver os laços institucionais com ele para evitar possíveis ações de retaliação.

Estratégias de binding visam a coibir os Estados mais fortes, por meio de acordos institucionais (Ikenberry: 2003). E, de fato, o Brasil (e os outros BRICs, em diferentes graus) mantêm ligaçôes com os Estados Unidos em uma variedade de áreas temáticas (Hirst: 2006). Os presidentes George W. Bush e Lula da Silva assinaram um acordo de cooperação em matéria de bio-combustíveis em março de 2007. Um acordo de cooperação nuclear civil entre os Estados Unidos e o Brasil foi concluído em 1990. Além disso, a Organização dos Estados Americanos (OEA) conecta Washington e Brasília, de várias maneiras, e os dois Estados foram os negociadores principais da Área de Livre Comércio das Américas (ALCA).

Pape (2005, 36-37) menciona negação territorial, diplomacia abrangente (entangling) e fortalecimento econômico como mecanismos de soft balancing. Estados-membro podem recusar o acesso ao seu território às forças terrestres dos Estados Unidos ou de trânsito para as suas forças aéreas e navais. O pedido da Secretária de Estado dos Estados Unidos Madeleine Albright foi rejeitado em 2002: ela pediu para Brasília o direito de usar bases de aeronaves brasileiras e de outras instituiçôes militares na região amazônica, mas Brasília recusou o estabelecimento de bases militares dos Estados Unidos em seu território, bem como a concessão de direitos de sobrevoo de aeronaves militares envolvidos no conflito colombiano (Flemes: 2006, 243). O Brasil também assumiu uma postura crítica em relação a um tratado bilateral sobre o uso de sete bases militares colombianas por parte das forças armadas dos Estados Unidos em setembro de 2009. A extensão do envolvimento militar dos Estados Unidos na América do Sul levou a disputas na União das Nações Sul-Americanas - Unasul (Flemes e Nolte: 2010). E, apesar do interesse persistente do Pentágono no caso indiano, não há bases militares estadunidenses na Índia, Rússia e China.

Os países do BRIC, juntamente com outros, têm utilizado as instituições internacionais para resistir a tentativas dos Estados Unidos de promover novas normas sobre o uso da força, incluindo a guerra preventiva, a soberania condicional, ou o direito de usar a força para promover mudança de regime (Hurrell: 2006, 11). Por se opor à invasão do Iraque em 2003 sem expresso mandato da Organização das Nações Unidas (ONU), os três Estados (e outras grandes potências) negaram a legitimidade à superpotência e tentaram frustrar seus planos de guerra, diminuindo 
o número de países dispostos a lutar ao lado dos Estados Unidos. O Brasil conseguiu apoiar muitos pequenos países latino-americanos em sua atitude de desaprovação, apesar da pressão considerável de Washington.

No entanto, os mais importantes instrumentos de política externa empregados pela nascente iniciativa BRIC será o que Paul $(2005,57)$ chamou de diplomacia abrangente e reforço da coesão econômica. Este último destina-se a mudança de poder econômico relativo por meio de blocos comerciais e cooperação em outros setores que aumentam o crescimento econômico dos membros ao mesmo tempo em que redirecionam o comércio, distanciando os não-membros. E o primeiro descreve o uso de regras e procedimentos das instituiçōes internacionais, a fim de influenciar a política externa do Estado primário:

De fato a soberania não pode ser cada vez mais definida pelo poder de isolar um estado de influências externas, mas sim pelo poder de participar efetivamente nas instituiçōes internacionais de todos os tipos. [...] Não há um grande enigma quanto às vantagens que muitas vezes levam Estados intermediários a favorecer o multilateralismo e instituiçōes [...]: o grau em que as instituiçôes oferecem espaço político [...], para estabelecer novas coalizōes para tentar afetar normas emergentes de forma congruente com seus interesses e para contrabalançar ou desviar as preferências dos mais poderosos, e a medida em que as instituiçôes oferecem voice opportunities para dar a conhecer os seus interesses e propiciam oferta de apoio político no mais amplo mercado de ideias (Hurrell: 2000, 3-4).

Brasil, Rússia, Índia e China utilizam as instituições de governança global para criar novas coligações voltadas a realizar interesses em comum.

A contribuição específica da política externa brasileira sob o comando de Lula da Silva consiste em colocar em prática, por meio da diplomacia, a autonomia a que foi visada por grande parte da comunidade de relações exteriores (Soares de Lima: 2008, 65). O último passo nesse sentido foi a formalização das relações entre os países BRIC (Brasil, Rússia, Índia e China) como um novo mecanismo para açōes conjuntas. De acordo com o ministro das Relaçōes Exteriores, Celso Amorim, esses quatro países estão tentando consolidar-se politicamente como um bloco que ajudará a equilibrar e democratizar a ordem internacional no começo do século (Amorim: 2008).

A iniciativa do BRIC é, porém, apenas o último exemplo: o fórum IBAS foi lançado na reuniāo do G8 de 2003, em Evian, e o G3 foi estabelecido durante o Assembleia Geral da ONU, no mesmo ano. A estratégia de utilizar as instituições internacionais para construir coalizôes Sul-Sul, culminou na criação do G21, com o seu amplo impacto reconhecido na governança econômica global, na conferência da OMC em Cancun. A Ronda de Doha, em especial, demonstra a capacidade das potencias emergentes para determinar a agenda institucional, a fim de influenciar normas internacionais emergentes em favor dos seus interesses. Além disso, o Brasil 
e a Índia são o quarto e quinto mais ativos atores no âmbito do mecanismo de solução de controvérsias da OMC.

Enquanto que as negociações da OMC pouco progrediram em termos de conteúdo, Brasil e outras potências emergentes têm sido capazes de melhorar suas posições na hierarquia do comércio internacional. Na conferência da OMC de 2004, em Genebra, Brasil e Índia foram convidados para integrar-se ao grupo de preparação G5 juntamente com a UE, os Estados Unidos e Austrália. E, na cúpula do G8 na Alemanha em 2007, Brasil, Índia e China (com a África do Sul e México) foram convidados para formalizar seu diálogo com o clube elitista dos países mais industrializados, por meio do chamado "Processo de Heiligendamm" ou processo O-5. Apesar de estes convites já refletirem a aceitação crescente do seu (potencial) status de grande potência pelas potências estabelecidas, a reunião de Pittsburgh do G20 em setembro de 2009 consagrou o papel protagonista dos países do BRIC e outras cinco economias emergentes da Ásia, África e América Latina (Indonésia, Coréia do Sul, África do Sul, Argentina e México). O G20 tornar-se-á o novo conselho permanente para a cooperação econômica internacional e irá substituir o G8 essencialmente, o qual continuará a atender as questôes de segurança importantes, mas terá influência reduzida.

Para resumir, o Brasil desempenha um papel-chave na multiplicidade das instituições globais (Guilhon de Albuquerque: 2006). Está fortemente integrado na ordem mundial e opera entre instituiçôes globais a fim de reforçar mudanças incrementais de poder. Finalmente, esta linha de ação destina-se a transformar a ordem global de maneira a permitir sua aspiração ao status de grande potência em médio prazo. Para atingir esta meta, a diplomacia brasileira está ativa e inovadora no desenvolvimento de novos processos de cooperação, como o G21, o IBAS e a iniciativa BRIC. Além disso, Brasília é descrita por muitos comentaristas políticos como a força condutora do G3 (Vinzentini: 2006). Brasil segue uma estratégia de "latente multi-institucionalização" (Flemes: 2009), que se reflete na sua onipresença no cenário mundial em alianças flexíveis, todas elas caracterizadas por baixos níveis de institucionalização (G3, G4, O-5, G21, G77). Esta estratégia garante um máximo de soberania nacional, flexibilidade e independência para a política externa brasileira.

\section{Perspectivas da iniciativa BRIC}

Em junho de 2009, teve lugar a última manifestação da latente multiinstitucionalização com a primeira cúpula presidencial dos países BRIC em Ekaterimburgo. É interessante ver como a iniciativa BRIC começou sendo um conceito analítico elaborado por Jim O’Neil, economista de Goldman \& Sachs, que achou um eco considerável na mídia e hoje é um competidor do processo O-5 do G8, processos iniciados pelas potências estabelecidas. A mais recente publicação da Goldman \& Sachs (2007) predisse que a China ultrapassará os Estados Unidos 
como economia maior do mundo no ano 2027 e que, além disso, o PIB somado dos países BRIC igualará o PIB de Japão, Alemanha, França, Inglaterra, Itália e Canadá (G7) em 2032. Apesar de estas predições de crescimento serem controversas por presumirem um desenvolvimento linear da economia global, a já mencionada ascensão dos países BRIC na hierarquia econômica global claramente confirma este prognóstico de tendência de mudança.

O que continua questionável é se estes acontecimentos podem construir uma base sólida para uma aliança econômica e política das naçôes BRIC, como se previu em Ekaterimburgo. Os ministros de relações exteriores dos países BRIC, desde 2006, tiveram reuniōes à margem de conferencias da ONU, mas a cúpula de Ekaterimburgo foi a primeira reunião formal e independente a demonstrar que estes países querem usar sua união para fins políticos. O sub-secretário para assuntos políticos, responsável pelas questôes do BRIC no Itamaraty, Roberto Jaguaribe, disse que em Ekaterimburgo o fundamental era dar início a um "mecanismo de integração entre os países BRIC que resulte num programa para a coordenação futura" (Estado de São Paulo, 20 de junho 2009). Neste sentido, grupos especializados do BRIC serão postos em marcha nas áreas prioritárias como a presente crise financeira e econômica, assuntos do FMI, reservas de divisas e o estímulo do comércio intraBRIC, finanças, investimentos, agricultura e segurança energética.

Na cúpula de Ekaterinburgo, a agenda formal pareceu ser menos importante que o êxito político do Kremlin, que consistiu em convocar um importante encontro de quatro nações com grandes recursos para contrabalançar os Estados Unidos. Alguns analistas vêem isto como uma resposta aos sinais que Washington tinha dado no sentido de que a Rússia já não é bem-vinda como membro do G8. John McCain, o candidato presidencial republicano nos Estados Unidos, exigiu a expulsão da Rússia do G8 pela sua falta de democracia e pediu a entrada do Brasil ou da Índia para substituí-la. O governo russo demonstrou que os clubes políticos podem ser formados com ou sem a participação dos Estados Unidos. Neste sentido, a cúpula claramente teve implicações geopolíticas, por exemplo, quando os ministros de relaçôes exteriores da China e da Índia se uniram à Rússia no apelo por um novo dialogo entre Sérvia e Kosovo sobre o status deste último. A UE e Estados Unidos reconheceram a independência do Kosovo em fevereiro de 2009, mas a Rússia tinha liderado a oposição contra a separação da Sérvia.

Outro assunto discutido na cúpula foi a introdução de uma moeda alternativa de reserva ou uma nova moeda global. Os países BRIC possuem na atualidade aproximadamente $40 \%$ das reservas de divisas. "A economia mundial não deveria permanecer enredada tão direta e imprecisamente nas vicissitudes de uma única potência mundial," disse Roberto Mangabeira Unger, ministro de assuntos estratégicos do Brasil. "Os países em desenvolvimento não deveriam ter que ver como as reservas de divisas que duramente acumularam, caem na esteira das grandes depreciações" (New York Times, 16 de junho 2009). China, Brasil e Rússia declararam recentemente que comprarão notas do Fundo Monetário 
Internacional para começar a diversificar suas reservas. Igualmente, a realidade é que os críticos do dólar também não veem uma alternativa imediata como moeda de câmbio no comércio mundial, já que não têm outros mercados no mundo que tenham a mesma profundidade e liquidez que o mercado dos Estados Unidos. E precisamente os quatro países BRIC têm economias e relações com os Estados Unidos consideravelmente diferentes, complicando assim os intentos de unir-se. Os quatro têm moedas que tinham sido historicamente instáveis ou que não são facilmente convertíveis e, além disso, a grande dependência da China quanto a exportações e suas enormes posses de ativos em dólares produzem um interesse em manter o status quo.

O mais claro e importante interesse comum dos países BRIC é sua demanda por uma maior representação e voz nas instituições financeiras internacionais, incluindo as designaçôes dos dirigentes destas instituiçôes com base em méritos e de forma transparente. Agora que os países BRIC representam 22\% da economia mundial, o presidente Lula da Silva declarou que chegou o tempo de as instituições multilaterais refletirem esta importância e que os países BRIC devem trabalhar em conjunto para "mudar a geografia política e comercial do mundo" (Reuters, 10 junho 2009). No intuito de conseguir isto, foi acordado que os países BRIC devem coordenar previamente antes das reuniōes do G20 e do G8 mais O-5, a fim de assegurar a reestruturação das instituições Bretton Woods. Adicionalmente, o grupo dos BRIC fez lobby em Ekaterimburgo para lograr a institucionalização da cúpula dos G20 já que esta proporciona um marco global mais democrático. O G20 não somente foi estabelecido alguns meses depois em Pittsburgh como foro central para a futura governança econômica, mas também decidiu dar um apoio político à mudança na representação dos países no FMI de pelo menos 5\% para os mercados emergentes. Quanto à reforma do Conselho de Segurança da ONU (Arraes: 2006), o presidente Lula da Silva comentou: "Os BRICs precisam estabelecer uma estratégia comum nas nossas negociações sobre a ONU com outros blocos" (ibid.). Mas este ponto não chegou a fazer parte da declaração final da cúpula presidencial dos BRIC.

Em termos de governança global, os membros do BRIC acordaram coordenar sua posição e propor abordagens construtivas na base do princípio de "responsabilidade compartida mas diferenciada" nas próximas negociaçôes com os países industrializados sobre a mudança climática em Copenhague. Afirmando que a segurança energética e a mudança climática são duas faces da mesma moeda, os países BRIC - como alguns dos maiores produtores e consumidores de energia - decidiram trabalhar para o desenvolvimento de uma arquitetura de comércio mundial de energia. $\mathrm{O}$ objetivo é promover possibilidades de financiamento e investimentos em infraestrutura energética com base em benefícios mútuos. Além disso, os países BRIC aspiram a uma diversificação progressiva das fontes de energia em direção a uma mistura de combustíveis incluindo combustíveis fósseis, energia renovável e energia nuclear, na base dos recursos tecnológicos de cada nação. 
Embora relativamente modesto, o volume de comércio entre os países BRIC tem aumentado nos últimos anos (Handelsblatt, 16 junho 2009). O mesmo se pode dizer sobre os investimentos intra-BRIC. Em Ekaterimburgo foram acordadas reduçõos de barreiras alfandegárias e não-alfandegárias, assim como uma "harmonização dos padrões" como medidas para estimular o comercio intra-BRIC. Os governos BRIC também consideraram estabelecer relações amplas com a África do Sul, para aumentar as possibilidades de comércio entre o Brasil e os outros três países, e, além disso, para avançar nas possibilidades econômicas dos quatro com sócios comerciais regionais de cada um dos países BRIC. Isto deverá levar à criação de uma rede que estimule o comércio e tratados de livre comércio a longo prazo.

No curto prazo, os BRIC estão longe de ser uma entidade política. A iniciativa BRIC é um grupo informal entre os foros internacionais, que se encontra para intercambiar seus pontos de vista e que, uma vez alcançado um acordo comum, defende sua posição. Mas assim como tem interesses comuns tais como reformar as instituiçõos multilaterais e contrabalançar as potências estabelecidas, o BRIC tem muitos assuntos que os dividem.

A China, cuja economia "lança sombra" sobre as dos demais três, depende da exportação de bens manufaturados para os Estados Unidos e a Europa. A Rússia vende petróleo, gás natural e outros recursos naturais ao estrangeiro. O Brasil concentra-se nas exportações agrícolas, enquanto o crescimento da Índia deve-se, em grande parte, a seu mercado interno. Os quatro países não comerciam muito entre si. Apenas cerca de $2 \%$ do comércio da China foi com a Rússia no ano passado apesar de serem vizinhos. Ao mesmo tempo, declarava o Brasil que a China tinha ultrapassado os Estados Unidos como seu maior sócio comercial. Os quatro países emergentes têm em comum o fato de que suas economias dependem em grande parte das tendências cíclicas das economias dos países industrializados. A crise econômica demonstra que os países BRIC, incluindo a Índia, não podem separar-se dos Estados Unidos, Europa ou Japão, visto que seus mercados internos não prosperam sem as exportações àqueles mercados.

As diferentes prioridades dos governos BRIC defendidas na cúpula manifestaram os futuros problemas que deverão enfrentar: Brasil, China e Índia tiveram como prioridade a reforma do sistema econômico e financeiro global, assim como os assuntos de segurança alimentar. O Brasil, em particular, desejava discutir as políticas agrícolas. Somente Brasil e Índia compartilham o interesse pela reforma do Conselho de Segurança da ONU. O interesse-chave da Rússia parecia ser contrabalançar os Estados Unidos assim como o dólar, ostensivamente provocando Washington. A Índia, por sua vez, necessariamente desejava evitar que a reunião BRIC se convertesse num foro para críticas aos Estados Unidos. Um forte elemento unificador de Brasil, Índia e Rússia no BRIC parece ser o interesse comum com relação à China, que é (potencialmente) um sócio comercial chave para todos eles.

Em resumo, fora temas pontuais, como o principio de "responsabilidades compartidas, mas diferenciadas" em relação a mudança climática, o que têm em 
comum os países BRIC é sobretudo a demanda de uma reforma multilateral por meio de soft balancing, em detrimento das grandes potências estabelecidas. Isto se aplica especialmente às instituiçôes de Bretton Woods e ao interesse dos países BRIC de subir na hierarquia econômica mundial. Mas como demonstrado acima, a iniciativa BRIC é somente uma a mais dentro de muitas outras, como o IBAS ou o G21. A estratégia de soft balanicng aplicada pelo Brasil e seus pares já marcou a ordem mundial dos últimos anos. Sua participação efetiva nas instituições globais por meio de parcerias informais, que são mais fáceis de se entrar do que o Conselho de Segurança da ONU, podem causar um impacto no caráter do multilateralismo e mais particularmente, nos seus procedimentos formais no longo prazo.

O estabelecimento do G20 como novo comitê condutor da economia global na cúpula de Pittsburgh em 2009, por um lado, refletiu esta nova forma de multilateralismo e, por outro, confirmou a chegada do Brasil e das outras potências emergentes ao clube dos tomadores de decisão. Os países BRIC tinham constado dentre os precursores mais fortes de mudança da diplomacia mundial e, por sua vez, beneficiam-se mais destas mudanças de poder global. Dentro da ordem global modelada pelas grandes potências por meio de instituiçōes internacionais, aqueles jogadores que operam efetivamente dentro destas como inovadores, formadores de alianças e porta-vozes, e que, ao mesmo tempo, conservam alto grau de soberania e independência têm o potencial de influir substancialmente os resultados de políticas futuras.

\section{Referências bibliográficas}

AMORIM, Celso. Os Brics e a reorganização do mundo. Tendências/Debates, 8/06/ 2008. ARRAES, Virgilio. O Brasil e a ONU, de 1990 a nossos dias: das grandes conferências às grandes pretensões. In: OLIVEIRA, H.; LESSA, A. (Org.). Relações internacionais do Brasil: temas e agendas (Vol. 2). São Paulo: Saraiva, 2006.

BONN INTERNATIONAL CENTER FOR CONVERSION (BICC). Conversion Survey 2008: Global Disarmament, Demilitarization, and Demobilization. Baden-Baden: Nomos, 2008.

BUZAN, Barry; WAEVER, Ole. Regions and Powers. The Structure of International Security. Cambridge: Cambridge University Press, 2003.

CAVERLEY, Jonathan D. United States Hegemony and the New Economics of Defence. Security Studies, Vol. 16, No 4, 2007, pp. 1-17.

CERVO, Amado Luiz. A ação internacional do Brasil em um mundo em transformação: conceitos, objetivos e resultados (1990-2005). In: OLIVEIRA, H.; LESSA, A. (Org.). Relaçôes internacionais do Brasil: temas e agendas (Vol. 1). São Paulo: Saraiva, 2006.

CHASE, Robert S.; HILL, Emily B.; KENNEDY, Paul. Pivotal States and U. S. Strategy. Foreign Affairs, Vol. 75, No 1, 1996, pp. 33-51.

COOPER, Andrew F.; ANTKEIWICZ, Agata (Ed.). Emerging Powers and Global Governance. Waterloo: Wilfried Laurier University Press, 2008. 
COX, Michael. Is the United States in Decline - Again? International Affairs, Vol. 43, No 4, 2007, pp. 643-653.

DINIZ, Eugenio. O Brasil e as operações de paz. In: OLIVEIRA, H.; LESSA, A. (Org.). Relações internacionais do Brasil: temas e agendas (Vol. 2). São Paulo: Saraiva, 2006.

FLEMES, Daniel. 2006. Brazil's Cooperative Leadership in Southern Latin America's Security Policies. Publicado em: [http://www.dissertation.de/englisch/index.php3?active_ document=buch.php3\&sprache $=2 \&$ buch $=4580]$. Disponibilidade: 15/3/ 2009 .

FLEMES, Daniel. Brazil's Strategic Options in a Multiregional World Order. Paper presented at the 1st Regional Powers Network (RPN) Conference "Ideas, Interests, Resources and Strategies of Regional Powers - Analytical Concepts in Comparative Perspective", German Institute of Global and Area Studies, Hamburg, September, 2008.

FLEMES, Daniel. Brazilian Foreign Policy in the Changing World Order, South African Journal of International Affairs, Vol. 16, No 2, 2009, pp. 161-82.

FLEMES, Daniel, ed. Regional Leadership in the Global System: Ideas, Interests and Strategies of Regional Powers, Aldershot: Ashgate, 2010.

FLEMES, Daniel; NOLTE, Detlef. Alianzas externas en armamento y defensa. Una nueva dimensión en la agenda de seguridad Latinoamericana. Foreign Affairs Latinoamérica, Vol. 10, No 1, pp. 1-13.

FRIEDBERG, Aaron L. Ripe for Rivalry: Prospects for Peace in a Multipolar Asia. International Security, Vol. 18, No 3, 1994, pp. 5-33.

GILPIN, Robert. War and Change in World Politics. Cambridge, Mass.: Cambridge University Press, 1981.

GUILHON DE ALBUQUERQUE, José Augusto. 2006. Os desafios de uma ordem internacional em transição. In: OLIVEIRA, H.; LESSA, A. (Org.). Relações internacionais do Brasil: temas e agendas (Vol. 1). São Paulo: Saraiva, 2006.

GOLDMAN SACHS. BRICs and Beyond. London: Goldman Sachs, 2007.

GREENFIELD PARTEM, Michael. The Buffer System in International Relations. The Journal of Conflict Resolution, Vol. 27, No 1, 1983, pp. 3-26.

GRIES, Peter Hays. China Eyes the Hegemon. Orbis, Vol. 49, No 3, 2005, pp. 401-412.

HAASS, Richard N. The Age of Nonpolarity: What will Follow U.S. Dominance? Foreign Affairs, Vol. 87, No 3, 2008, pp. 44-56.

HAKIM, Peter. 2004. The Reluctant Partner. Foreign Affairs, Vol. 83, No 1, 2004, pp. 114-123.

HIRST, Mônica. Os cinco "As" das relações Brasil-Estados Unidos: aliança, alinhamento, autonomia, ajustamento e afirmação. In: OLIVEIRA, H.; LESSA, A. (Org.). Relações internacionais do Brasil: temas e agendas (Vol. 1). São Paulo: Saraiva, 2006.

HIRST, Mônica. Brazil India Relations: A Reciprocal Learning Process. South Asian Survey, Vol. 15, No 1, 2008, pp. 143-164.

HUMPHREY, John; MESSNER, Dirk. Instabile Multipolarität: Indien und China verändern die Weltpolitik. DIE Analysen und Stellungnahmen No 1. Bonn: Deutsches Institut für Entwicklungspolitik, 2006. 
HUNTINGTON, Samuel. The Lonely Superpower. Foreign Affairs, Vol. 78, No 2, 1999, pp. 35-49.

HURRELL, Andrew. Some Reflections on the Role of Intermediate Powers in International Institutions. Working Paper No 244 "Paths to Power: Foreign Policy Strategies of Intermediate States", pp. 23-41. Washington, D.C.: Latin American Program, Woodrow Wilson International Centre, 2000.

HURRELL, Andrew. 2006. Hegemony, Liberalism and Global Order: What Space for Would-be Great Powers? International Affairs, Vol. 82, No 1, pp. 1-19.

HURRELL, Andrew. On Global Order: Power, Values and the Constitution of International Society. Oxford: Oxford University Press, 2007.

HURRELL, Andrew. Regional Powers and Global Order - Project Overview. Unpublished Draft. Oxford, 2009.

HURRELL, Andrew. Brazil and the New Global Order. Current History, Vol. 109, No 724 , 2010, pp. 60-68.

IKENBERRY, G. John. 2003. Strategic Reactions to American Pre-eminence: Great Power Politics in the Age of Unipolarity. Publicado em: [http://www.odci.gov/nic/confreports_ stratreact.html]. Disponibilidade: 15/03/ 2009.

IKENBERRY, John. After Victory: Institutions, Strategic Restraint, and the Rebuilding of Order After Major War. Princeton, N.J.: Princeton University Press, 2001.

IKENBERRY, John. The Rise of China and the Future of the West. Foreign Affairs, Vol. 87, No 1, 2008, pp. 22-37.

IKENBERRY, John; MASTANDUNO, Michael; WOHLFORTH, William C. Introduction: Unipolarity, State Behavior, and Systematic Consequences. World Politics, Vol. 61, No 1, 2009, pp. 1-27.

IKENBERRY, G. John; WRIGHT, Thomas. Rising Powers and Global Institutions. New York: The Century Foundation, 2008.

JAGUARIBE, Helio. O Nacionalismo na Atualidade Brasileira, Rio de Janeiro: Editora Universitaria Candido Mendes, 2005.

KAGAN, Robert. The Return of History and the End of Dreams. London: Atlantic Press, 2008.

KEOHANE, Robert O. After Hegemony: Cooperation and Discord in the World Political Economy. Princeton, N.J.: Princeton University Press, 1984.

LAKE, David A. Escape from the State-of-Nature: Authority and Hierarchy in World Politics. International Security, Vol. 32, No 1, 2007, pp. 47-79.

LEVY, Jack S. Balances and Balancing: Concepts, Propositions and Research Design. In: VASQUEZ, J.; ELMAN, C. (Org.). Realism and the Balance of Power: A New Debate. Saddle River, N.J.: Prentice-Hall, 2003, pp. 128-153.

LIEBER, Keir A.; ALEXANDER, Gerard. 2005. Waiting for Balancing: Why the World is Not Pushing Back. International Security, Vol. 30, No 1, 2005, pp. 109-139.

MAHBUBANI, Kishore. The New Asian Hemisphere: The Irresistible Shift of Global Power to the East. New York: Public Affairs, 2008.

MALAMUD, Andrés. Leadership without Followers: The Contested Case for Brazilian Power Status. In: REZENDE MARTINS, E.; GOMES SARAIVA, M. (Org.). Brasil - União 
Europeia - América do Sul. Anos 2010-2020. Rio de Janeiro: Editorial Konrad-AdenauerStiftung, 2009.

MEARSHEIMER, John J. The Tragedy of Great Power Politics. New York: W. W. Norton, 2001.

NOLTE, Detlef. Ideas, Interests, Resources and Strategies of Regional Powers. Paper presented at the 1st Regional Powers Network (RPN) Conference "Ideas, Interests, Resources and Strategies of Regional Powers - Analytical Concepts in Comparative Perspective", German Institute of Global and Area Studies, Hamburg, September, 2008.

NYE, Joseph S. Soft Power. The Means to Success in World Politics. New York: Public Affairs, 2004.

OLIVEIRA, Henrique Altemani; LESSA Antônio Carlos (Ed.). Relações internacionais do Brasil: temas e agendas (Vol.1 e 2). São Paulo: Saraiva, 2006.

ORGANKSI, A.R.F.; KUGLER, Jacek. The War Ledger. Chicago, I.L.: Chicago University Press, 1980.

OVERHOLT, William H. Asia, America and the Transformation of Geopolitics. Cambridge: Cambridge University Press, 2008.

PAPE, Robert A. Soft Balancing against the United States. International Security, Vol. 30, No 1, 2005, pp. 7-45.

PAUL, T.V. Soft Balancing in the Age of U.S. Primacy. International Security, Vol. 30, No 1, 2005, pp. 46-71.

PINHEIRO GUIMARAES, Samuel. Desafios Brasileiros na Era dos Gigantes, São Paulo: Contraponto Editora Ltda, 2006.

REZENDE MARTINS, Estevão C.; GOMES SARAIVA, Miriam (Ed.). Brasil - União Europeia - América do Sul. Anos 2010-2020. Rio de Janeiro: Editorial Konrad-AdenauerStiftung, 2009.

SHAW, Timothy M.; COOPER, Andrew F.; CHIN, Gregory T. Emerging Powers and Africa: Implications for/ from Global Governance. Politikon, Vol. 36, No 1, 2009, pp. 27-44.

SLAUGHTER, Anne-Marie. Power in the Networked Society. Foreign Affairs, Vol. 88, No 1, 2009, pp. 94-113.

SOARES DE LIMA, Maria Regina. Brasil en América Latina. América del Sur. Foreign Affairs En Espanol, Vol. 7, No 4, 2007.

SOARES DE LIMA, Maria Regina. Brazil Rising. Internationale Politik Global, Vol. 9, No 3, 2008, pp. 62-67.

SOARES DE LIMA, Maria Regina; HIRST, Mônica. Brazil as a Intermediate State and Regional Power: Action, Choice and Responsibilities. International Affairs, Vol. 82, No 1, 2006, pp. 21-40.

SOARES DE LIMA, Maria Regina; HIRST, Mônica. Brasil, India e Africa do Sul: Desafios e oportunidades para novas parcerias. São Paulo: IUPERJ, 2009.

STOCKHOLM INTERNATIONAL PEACE RESEARCH INSTITUTE (SIPRI). SIPRI Yearbook 2008: Armaments, Disarmament, and International Security. Oxford: Oxford University Press, 2008.

TAMMEN, Ronald L. et al. Power Transitions Strategies for the 21st Century. New York: Chatham House Publishers, 2000. 
VIZENTINI, Paulo. O G-3 e o G-20: o Brasil e as novas coalizões internacionais. In: OLIVEIRA, H.; LESSA, A. (Org.). Relações internacionais do Brasil: temas e agendas (Vol. 2). São Paulo: Saraiva, 2006.

WALTZ, Kenneth N. Structural Realism after the Cold War. International Security, Vol. 25, No 1, 2000, pp. 5-41.

WILSON, Dominic; PURUSHOTHAMAN, Roopa. Dreaming With BRICs: 2050. Global Economics Paper No 99. New York: Goldman Sachs, 2003.

WOHLFORTH, William C. The Stability of a Unipolar World. International Security, Vol. 24, No 1, 1999, pp. 5-41.

ZAKARIA, Fareed. The Post-American World. New York: W.W. Norton \& Company, 2008.

Recebido em 14 de dezembro de 2009

Aprovado em 16 de março de 2010

\section{Resumo}

As opções de política externa do Brasil são limitadas, tendo em conta os recursos materiais superiores das grandes potências establecidas. Soft balancing envolve estratégias institucionais, tais como a formação de coalizões ou ententes diplomáticas limitadas, como BRIC, para restringir o poder das grandes potências estabelecidas. Os países BRIC tinham constado dentre os precursores mais fortes de mudança da diplomacia mundial e por sua vez se beneficiam mais destas mudanças de poder global. Dentro da ordem global modelada pelas grandes potências por meio de instituições internacionais, aqueles jogadores que operam efetivamente dentro destas como inovadores, formadores de alianças e porta-vozes, e que ao mesmo tempo conservam soberania e independência têm o potencial de influir sustancialmente os resultados de políticas futuras.

\section{Abstract}

The foreign policy options of Brazil are limited in view of the superior hard power of the established great powers. Brazil's soft balancing strategy involves institutional strategies such as the formation of limited diplomatic coalitions or ententes, such as BRIC, to constrain the power of the established great powers. The BRIC states have been amongst the most powerful drivers of incremental change in world diplomacy and they benefit most from the connected global power shifts. In a global order shaped by great powers through international institutions, those players who effectively operate within them as innovators, coalition builders and spokesmen while preserving great amounts of sovereignty and independence have the potential to substantially influence the outcomes of future global politics.

Palavras-chave: Brasil; BRIC; grandes potências; soft balancing; ordem global.

Key-words: Brazil; BRIC; great powers; soft balancing; global order. 